$$
\text { د. أبي الوتار }
$$

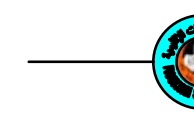

بصن الآثار المائية - الفتصالية المحتملة النالجة عن إنشاعسد أليسو. في إلبار مشروع إعمارجنوبشرق الألنافنط (GAP)

\author{
الكنور لب الوتار \\ كلية الإدارة والاقتصاد - جلمعة الموصل المبار
}

مستخلص البهث

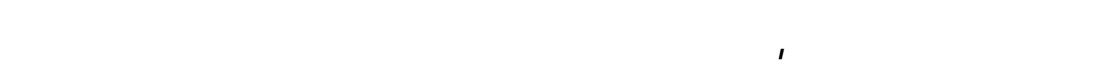

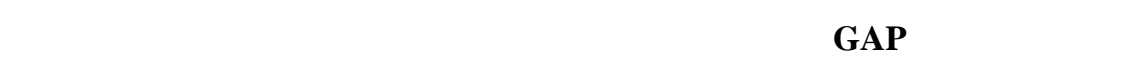

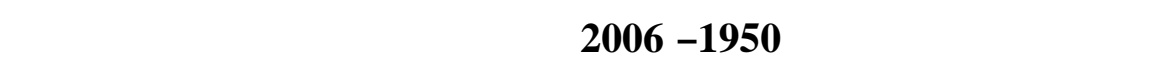

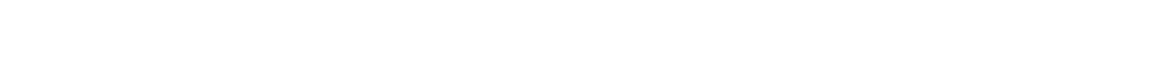

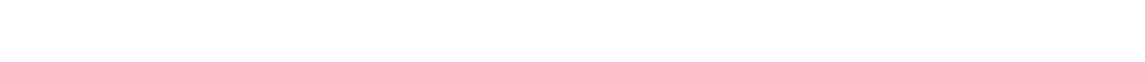

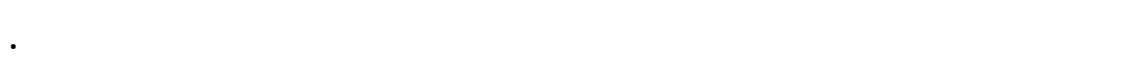

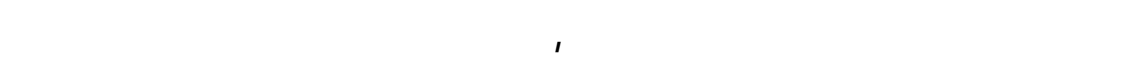

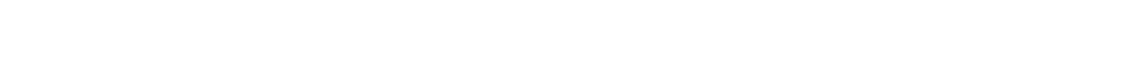

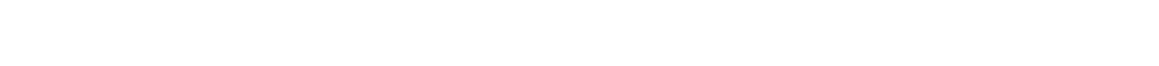

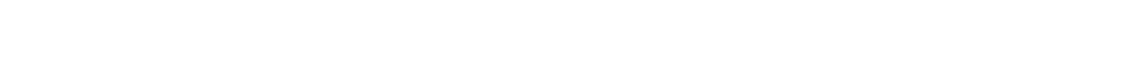

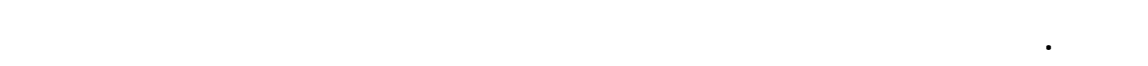

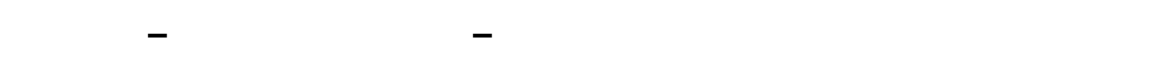

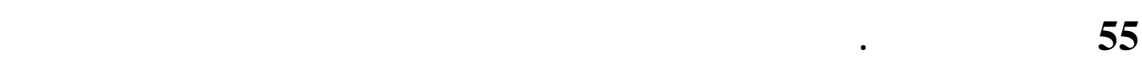

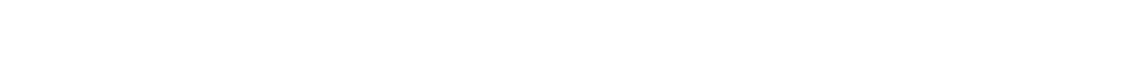

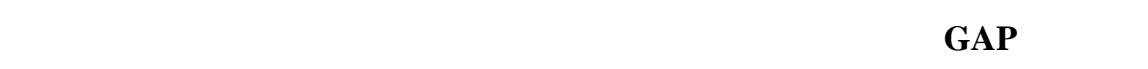

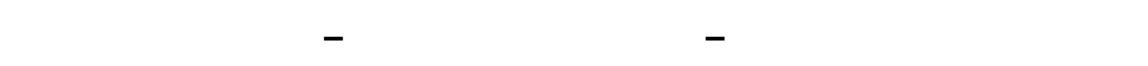

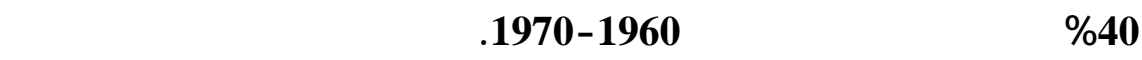

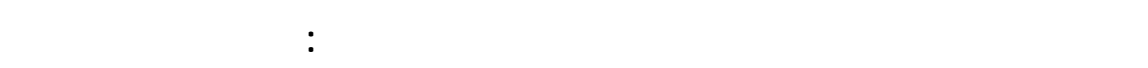


درلسك إقليمية 5 (12)

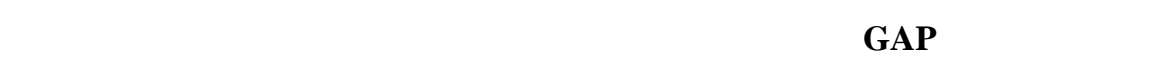

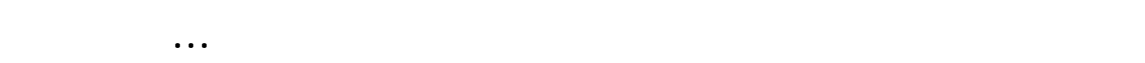

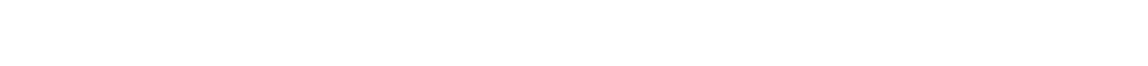

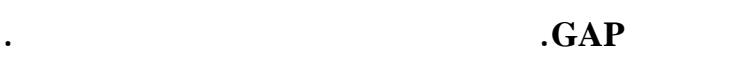

كالملتففتلحيه: النمو للسكاني، الطالة الإنتلجية الزراعية، الأراضي المروية، إنتاج الحب ـوب، إء الة

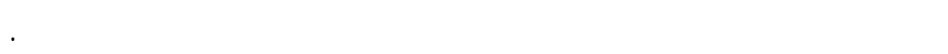




\section{مقدة وهف الررلسة}

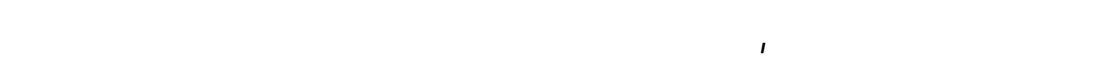

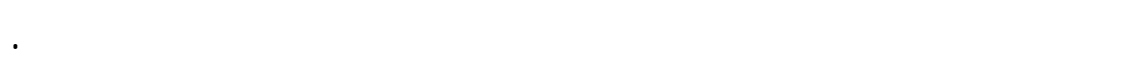

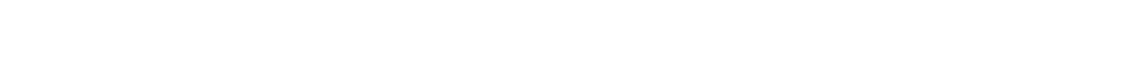

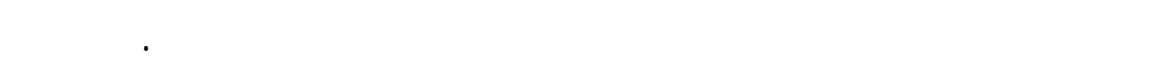

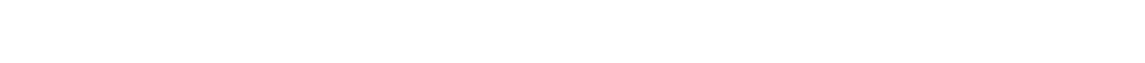
لنثاؤها على نهري نجلة والفرات منذ علم 1977، وما مرتبط بها من قالم

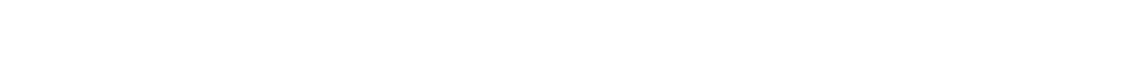

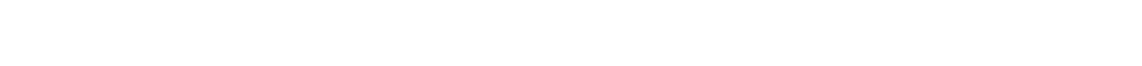

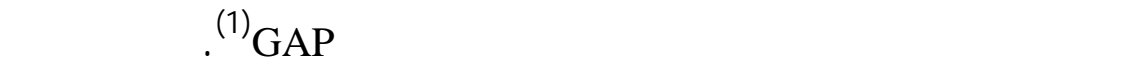

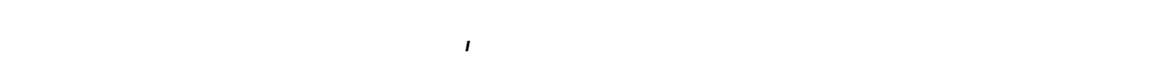
لمشروع GAP، بما فيهاسد عند أليسو الشكل 1):

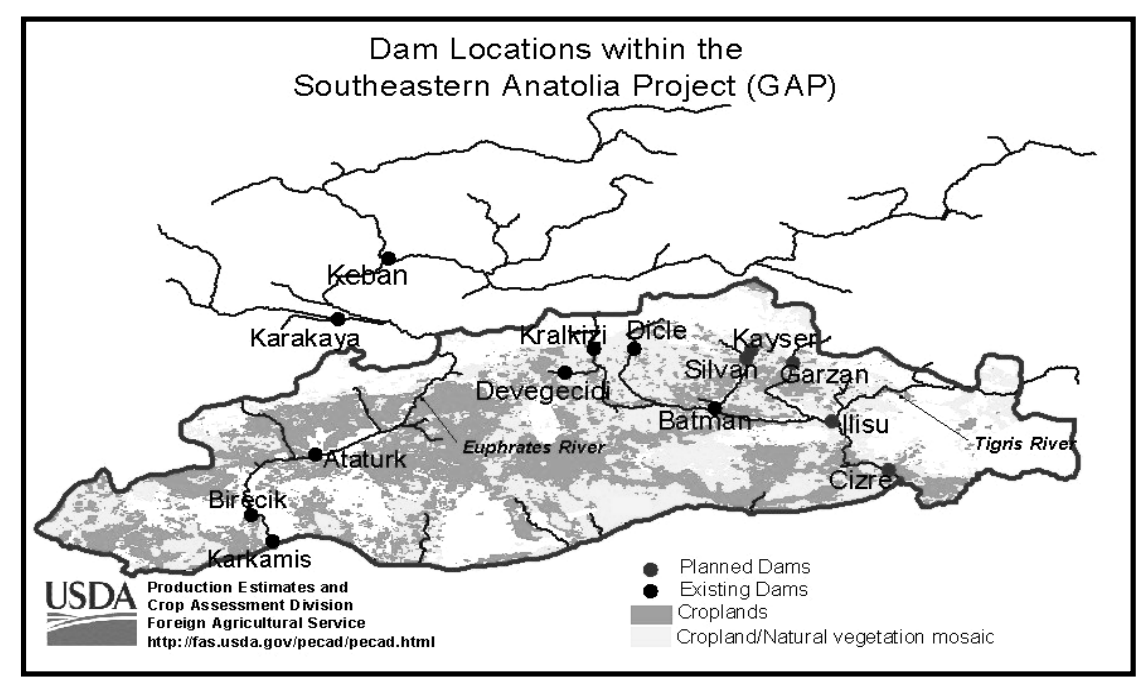

ششلى (1): المولفع الجغرلية لعدمن اللسود المزمع إنشاؤها, والمنجزة ضمن مشروع إعمارجنوب

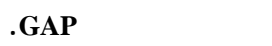
ملاطة: الدولئر الحمراعسدود يجري الهلى بإنشائها أومضطا لذك. 


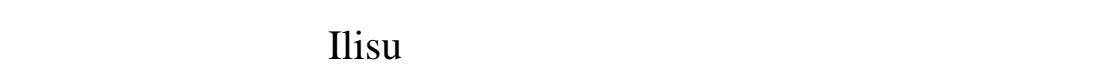

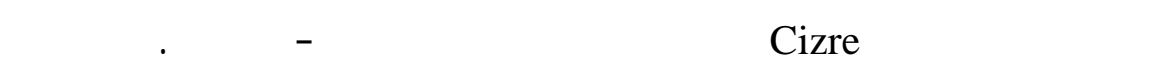

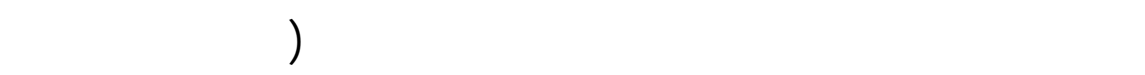

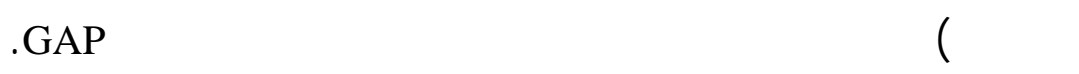
هذف الدرلسة: إن الهذف الرئيسي لهذه الدرلسة الإسطلاعية ذوشقين. الأول خاص

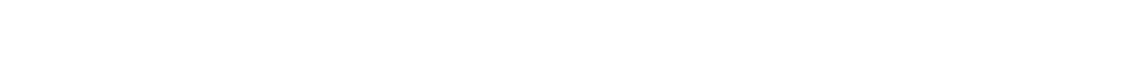

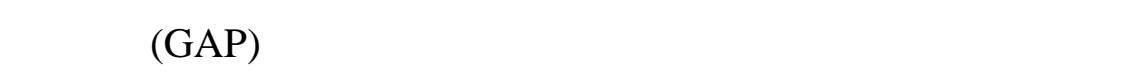

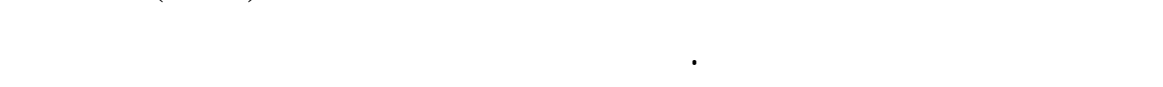

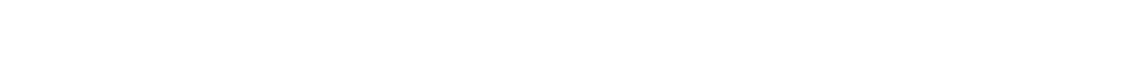

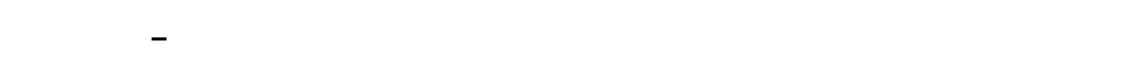
(لاجلة) والحدود العراقية-اللسورية (لنهر الفرات)، المعأ.

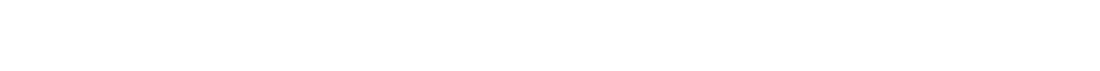

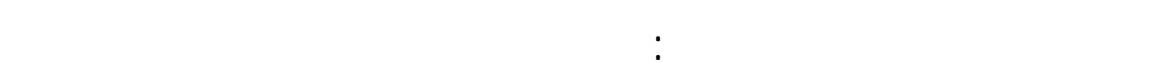

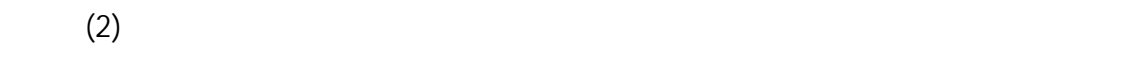

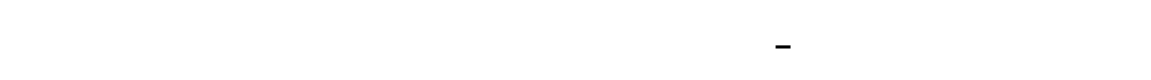

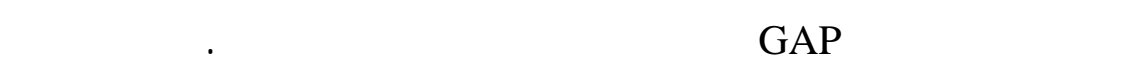

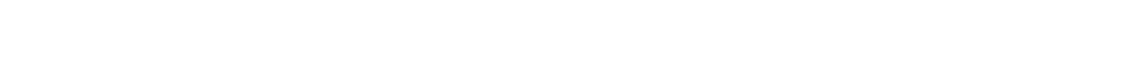

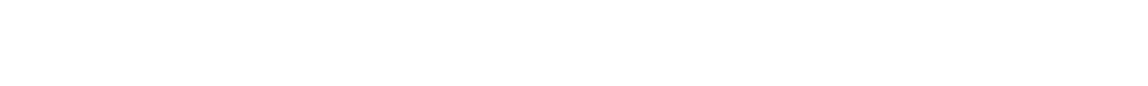

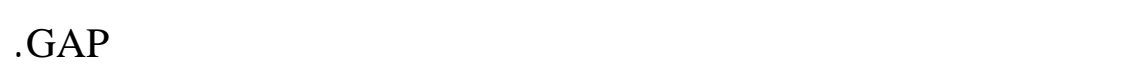

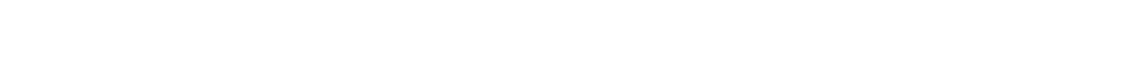

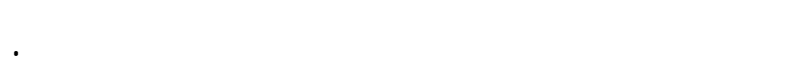




\section{(1) الماذلسد أليسو؟}

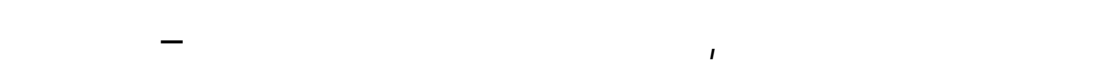

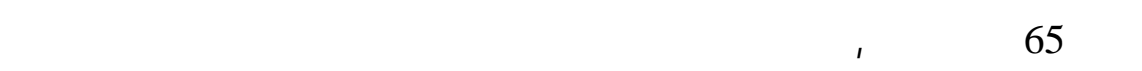

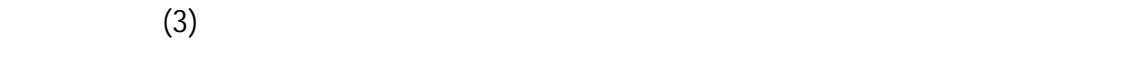

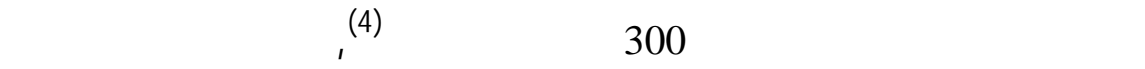

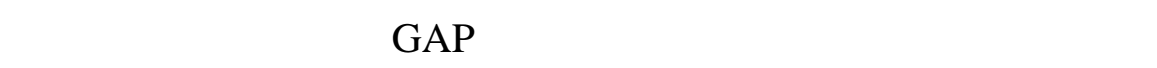

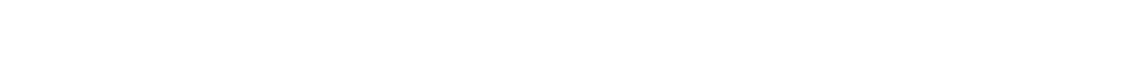

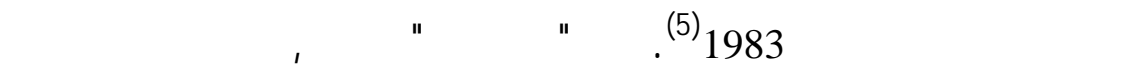

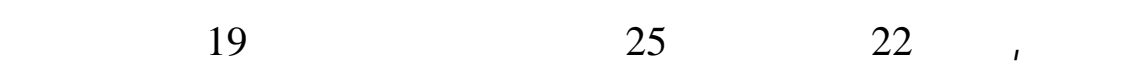

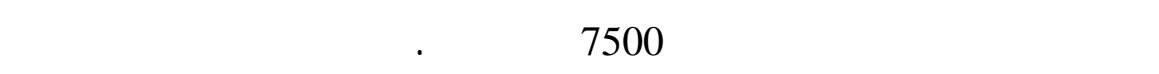

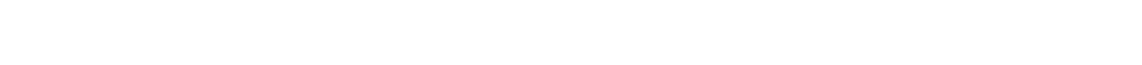

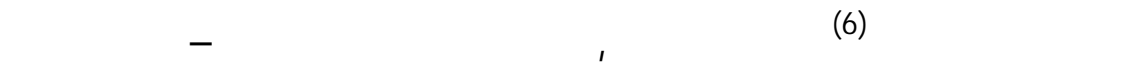

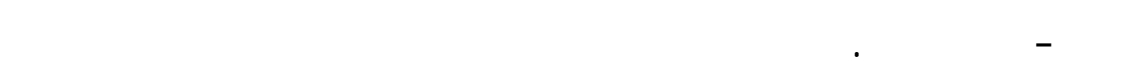

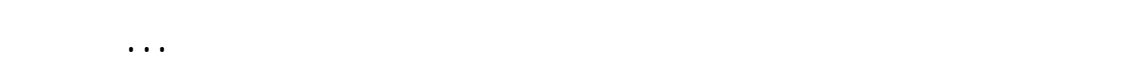
شهنته هذه الدول خلال الفترة 1950-2006, وتشهره الآن....

\section{أليسوفي بلبار مشروع GAP والنمو اللسكاني فتركيا للفت رة 1950 -}

:2006

شهدت تركيا خلل الفترة 1950 -2006 زيادسكانية ملفتة, ص الحبها

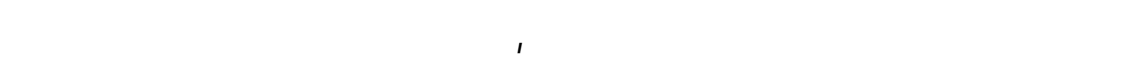

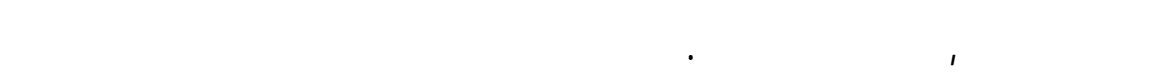

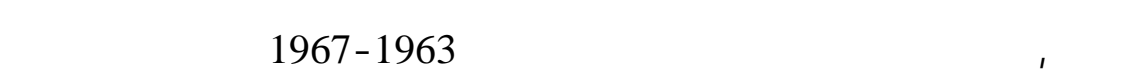

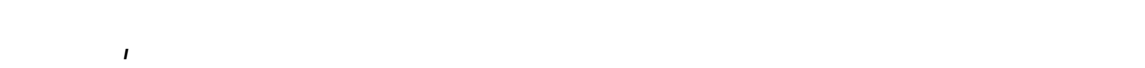

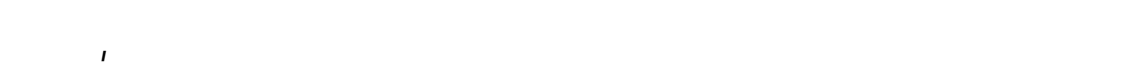

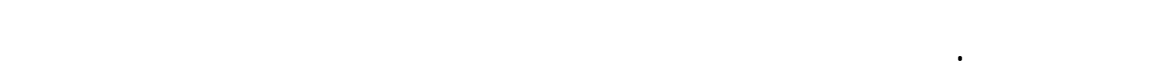


العلملة والتوظف في تركيا لمنوات مختارة ضنمن الفترة المش ار إليه L

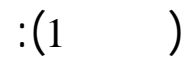
جدط (1): السكلن, الفوى العاملة ومسل البالة في تركيا للسنولت 1950، 1975، 2000، 2006

\begin{tabular}{|c|c|c|c|c|c|}
\hline 2006 & 2000 & 1975 & 1950 & 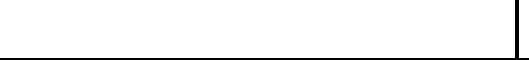 & ت \\
\hline 73.9 & 66.7 & 41.2 & 21.5 & | عدد اللسكل الكلي (مليهن نسمة) & 1 \\
\hline a 49.1 & 43.2 & 17.1 & 5.3 & |سككل المنلاق الحضربة (مليون نسمة) & 2 \\
\hline${ }^{\mathrm{a}} 67.3$ & 64.8 & 41.6 & 24.7 & (\%) & \\
\hline${ }^{\mathrm{a}} 24.7$ & 22.7 & $\mathrm{~b}^{\mathrm{b}} \mathbf{1 3 . 6}$ & ${ }^{b} 7.1$ & الفوى العاملة (مليونشخص) & 3 \\
\hline${ }^{\mathrm{a}} 22.3$ & 21.2 & .. & .. & عدد المشتغلين والهشتغلات (مليونشخص) & 4 \\
\hline a 9.9 & 6.4 &.. &. & |معل البلالة الرسمي' (\%) & 5 \\
\hline
\end{tabular}

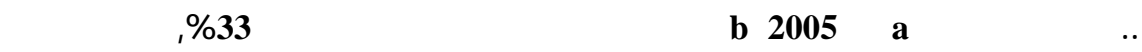

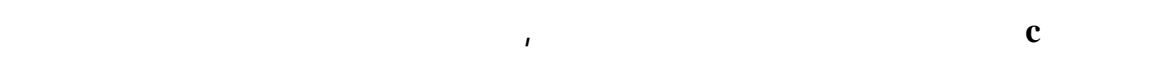

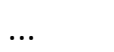

Source: UN, World Population Prospects, The 2004 Revision, Population Data Base (http://csa.un.org/unpp); UNDP, Human Development Report 2007/2008 (New York, United Nations Development Programme, 2007; earlier issues (http://hdr.undp.org).

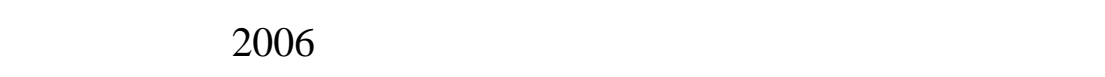

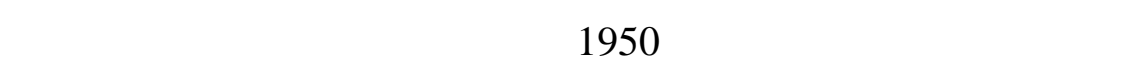

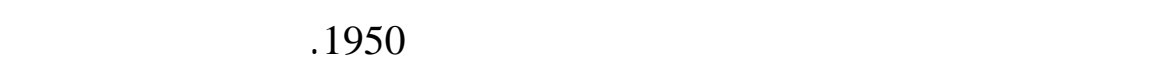

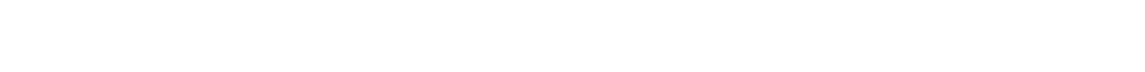

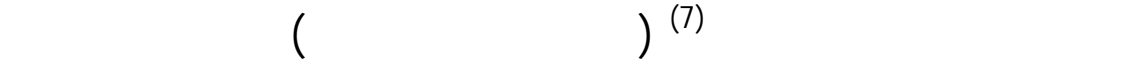

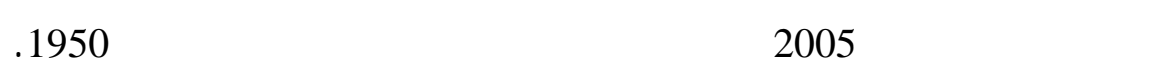

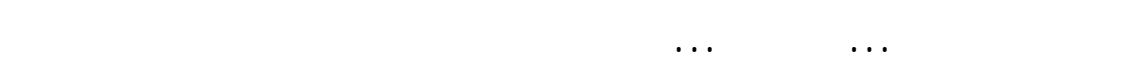


في ميزان المسابت الجارية, فلإن هذه الزياة لستلزمت وتستلزم, من بين الأشياء الأخرى, ما يلي: الميات الجيات

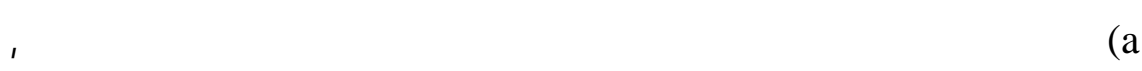

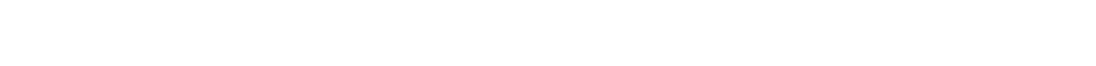

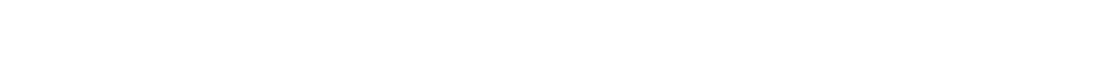

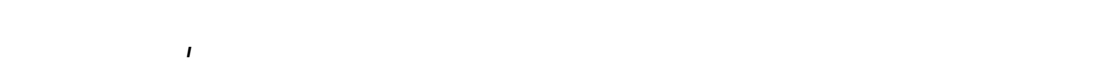

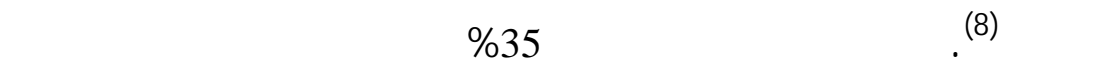

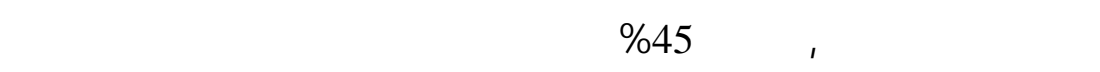

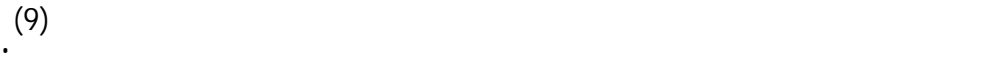

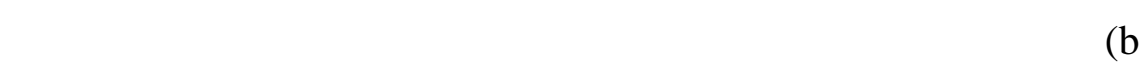

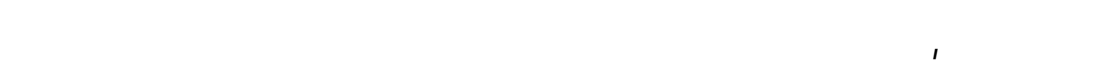

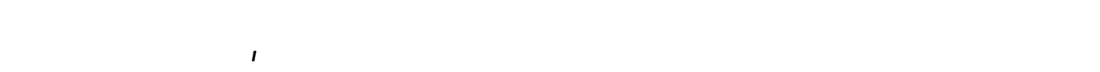

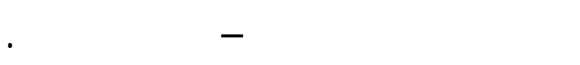

\section{جهود تنموبة في لبار مشروع GAP ومحدونية مي d نه ري نجل ة والفرات}

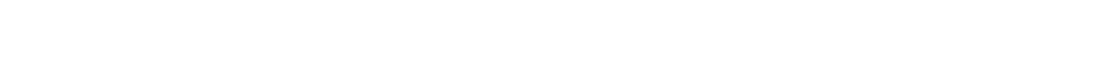

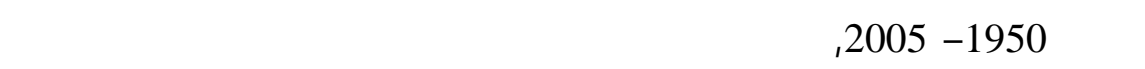

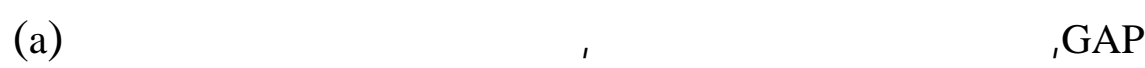

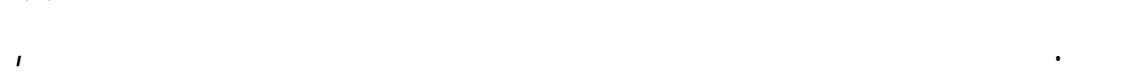
وبالموضوع الرئيسي لهذه الدرلسة من جهة لخريائ لخرى (جدول 2): 
جرط (2): المساحة المروبة (a), إنتاج الحطة والحبوب, والمعل المنوي الممك ن لتصرف ميل نهري نجلة والفرات في تركيا لمنولت مختارة

\begin{tabular}{|c|c|c|c|c|c|c|}
\hline 2004 & 2000 & 1990 & 1975 & 1950 & بيلن & ت \\
\hline${ }^{\mathrm{e}} 5.2$ & d 4.7 & ${ }^{\mathrm{c}} 4.0$ & $b_{2.7}$ & .. & الهساحة المروبة (مليهن هكتار) & 1 \\
\hline 34.1 & ${ }^{d_{30.2}}$ & ${ }^{\mathrm{c}} 25.2$ & 22.2 & 7.7 & إنتاج الحبوب (مليهنطن) & 2 \\
\hline 21.0 & 21.0 & 20.0 & 14.8 & 3.9 & إنتاج الهفلة (مليهنطن) & 3 \\
\hline 55.0 & 55.0 & 55.0 & 55.0 & 55.0 & معرل التصرف اللسنوئ (مليار & 4 \\
\hline
\end{tabular}

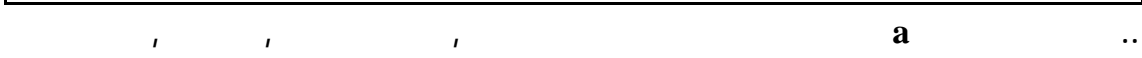

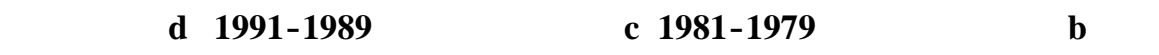
لالسنول

Source: UN, Statistical Yearbook 2001 and earlier issues; UN, FAO Indicator Tables (http://faostat.fao.org/site/339/default.aspx); FAO, Compendium of Food and Agricultural Indicators 2006. Available at (http://www.fao.org/statistics/ Compedndium_ 2006/ defult.asp); Singer, M. The Economic Advance of Turkey 1938-1960 (Ankara: Turkish Economic Association, 1977), especially pages 105, 214, and 236.

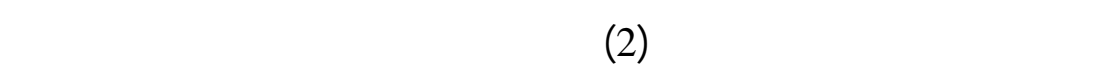

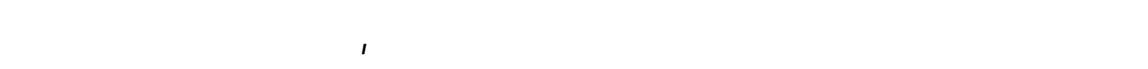

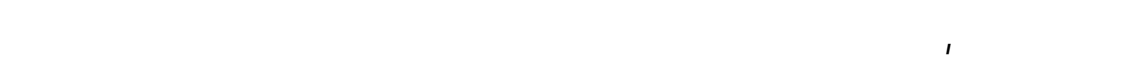

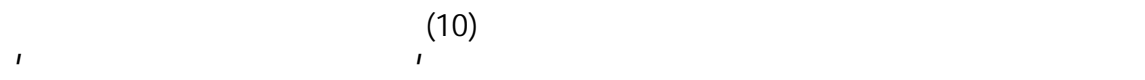

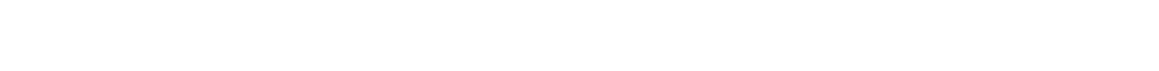

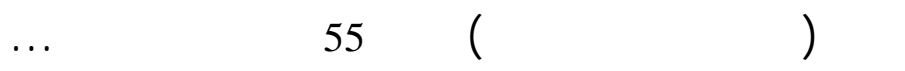




\section{(2) بهض الآثار المائية - الاغتصالية غير المرغومة}

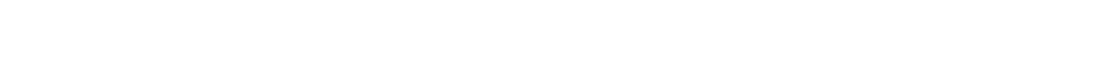
قل الحكومة التركية خلا الفترة 1950 -2005, بما في ذلك المالس السعي لإنشاء

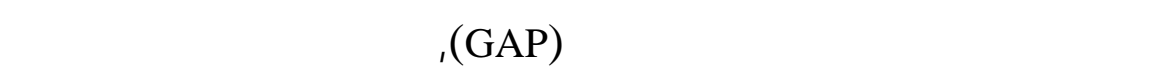

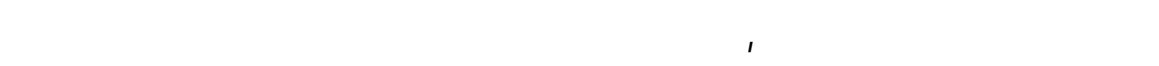
المعدل. في هذا القسم من الدرلسةسيكون التركيز على الجانين الت الينين

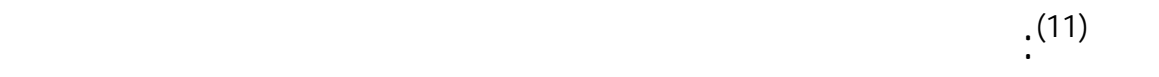

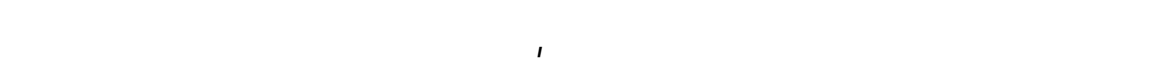

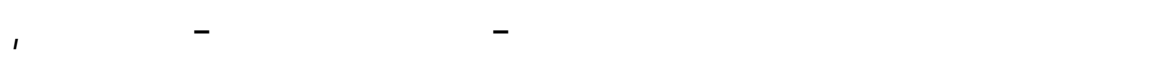

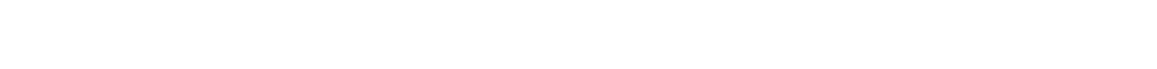

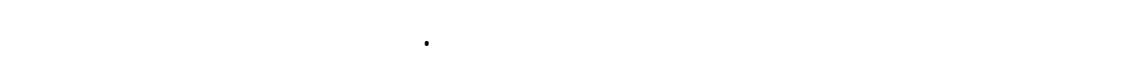

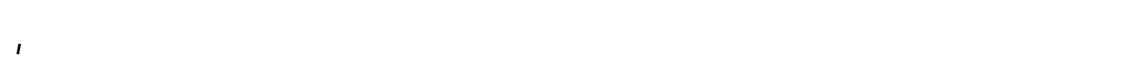

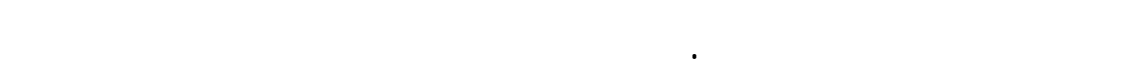

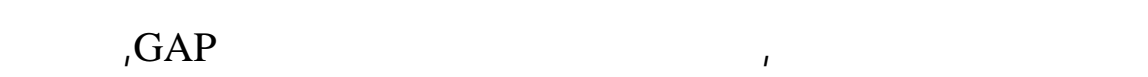
عملية إعاة إعمار الأهوار في جنوب العراق.

\section{ألولاًتسد أليسور, ششروع GAP وحصة العراق من ميل نه ـري نجل ة}

$$
\text { والفرات }
$$

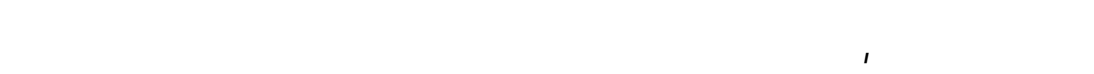

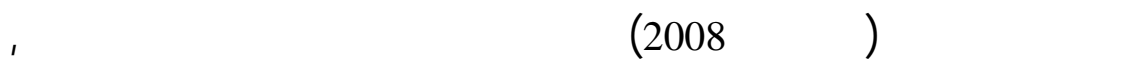

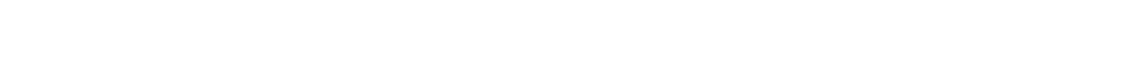

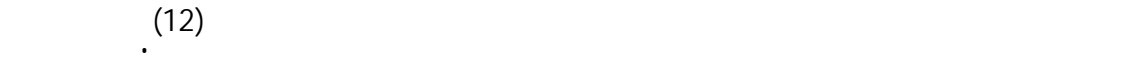

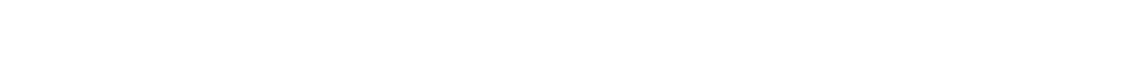
الثلاث, والقفيتين جزئيتين. الإقلقية الأوله وقهت في تموز 


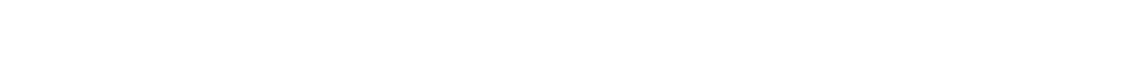

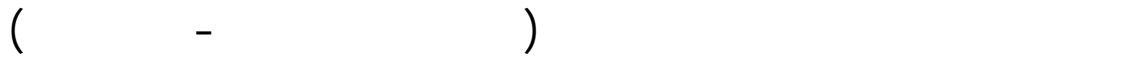

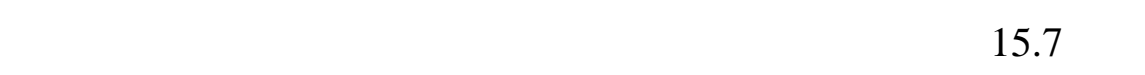

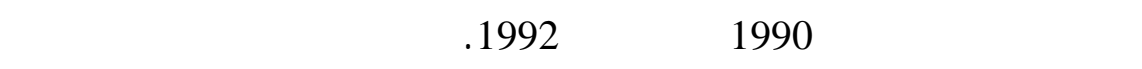

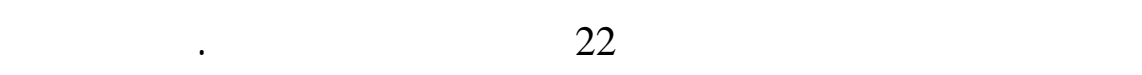

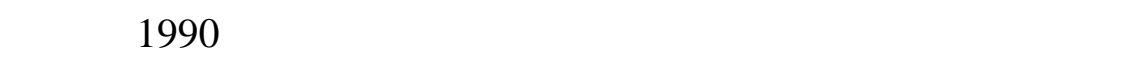

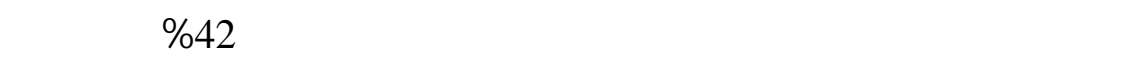

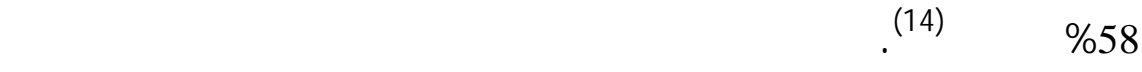

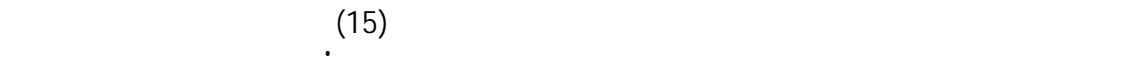

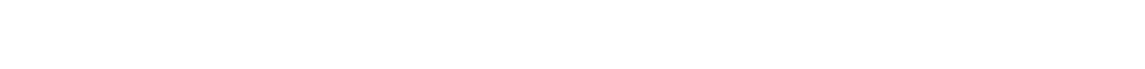

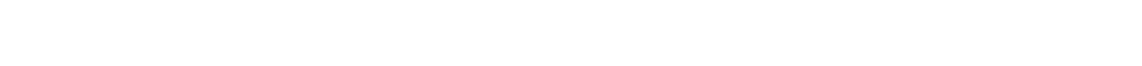

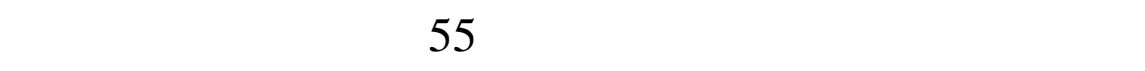

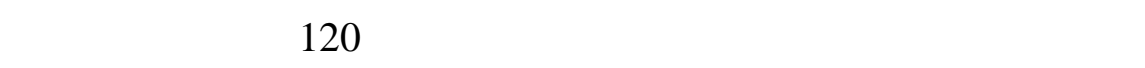

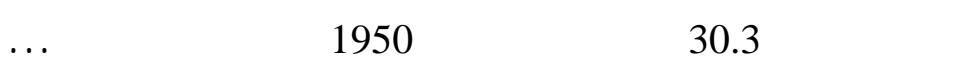

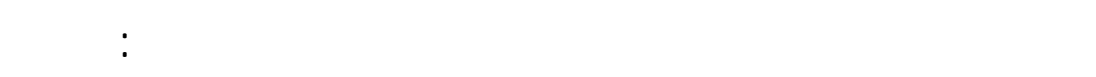

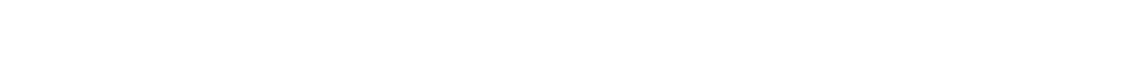

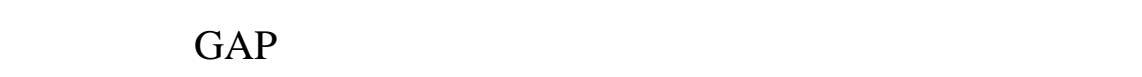

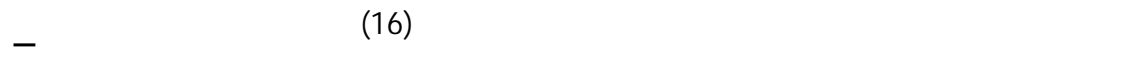

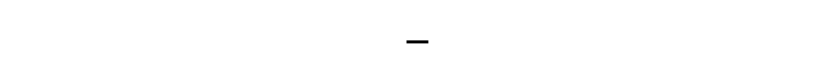

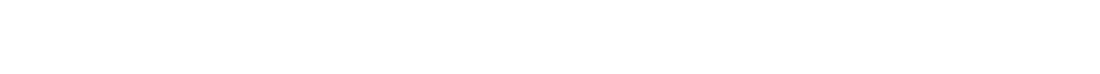

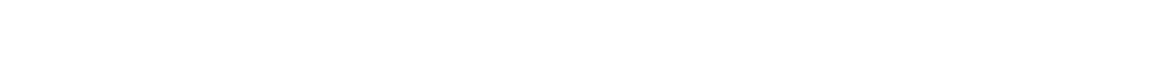

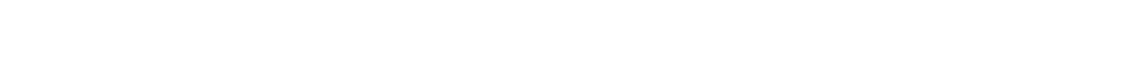
للسؤل أعلاه بشقيه من خلال الجدول الجابة علي درجة الآتي (جدول 3) . 


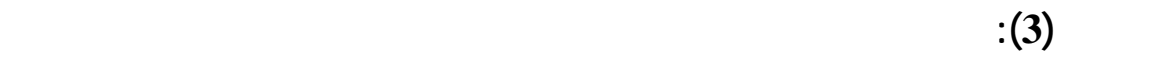

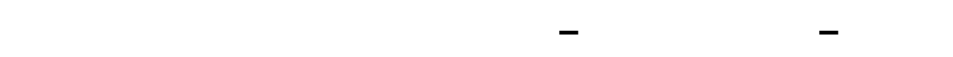

وفنشת ع

\begin{tabular}{|c|c|c|c|c|}
\hline \multicolumn{3}{|c|}{ مطل النفق اللسنوي (مليارمترمكمب) } & \multirow{2}{*}{ بيلن } & \multirow[b]{2}{*}{ ت } \\
\hline للانهرin & لنهر الفرات & لنهر نجلة & & \\
\hline 54.7 & 36.2 & 18.5 & عند الح دود الفت ـرة 1960 - & 1 \\
\hline $\begin{array}{l}31.1 \\
29.5\end{array}$ & $\begin{array}{l}12.8 \\
12.8\end{array}$ & $\begin{array}{l}18.5 \\
16.7\end{array}$ & 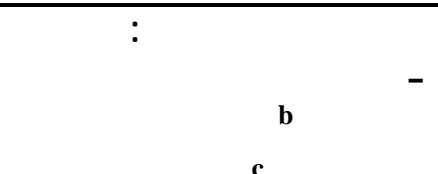 & 2 \\
\hline 21.1 & 9.6 & 11.5 & 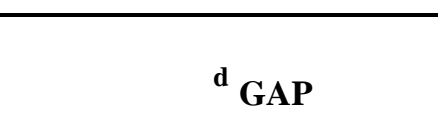 & 3 \\
\hline
\end{tabular}

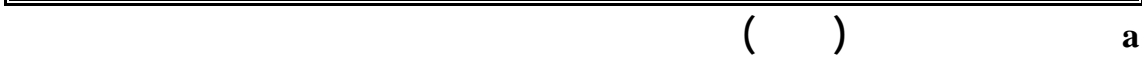

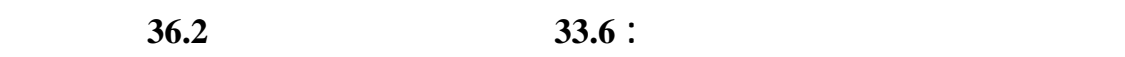

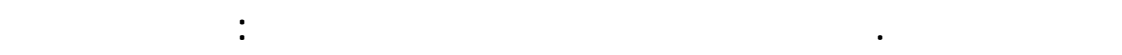

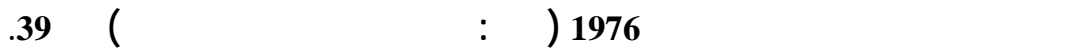

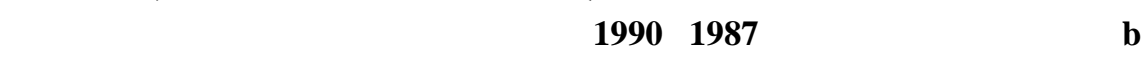
التواله. أنمار إلح:

Kundell, J. (ed.), "Water Profile of Turkey" (http://www.eoearth.org/article/Water_ profile_of_Turkey), Table (1). Accessed February 8 2007; Postal, Ibid., PP.80-83; Richter, et al., Ibid., PP.171-172, 182.

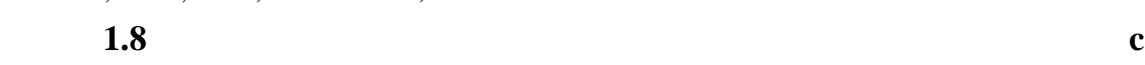

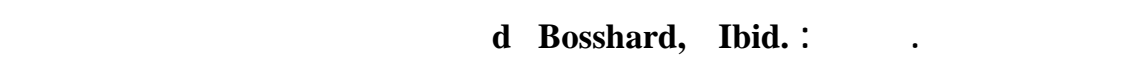

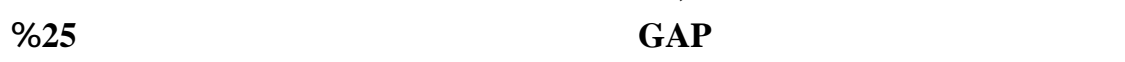

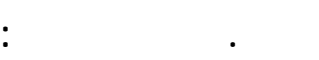

Kundell, Ibid.; Postal, Ibid.; \& Richter, et al., Ibid. 
إن ما جاء في الجدول أعلاه من بيانلت إحصائية، عل م مح دوسيتها،

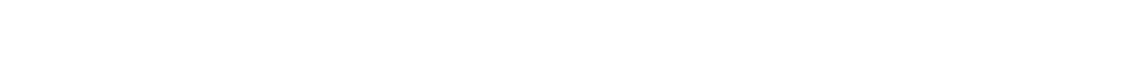

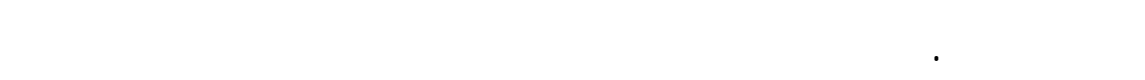

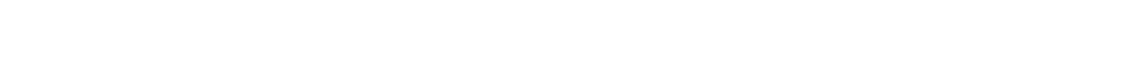

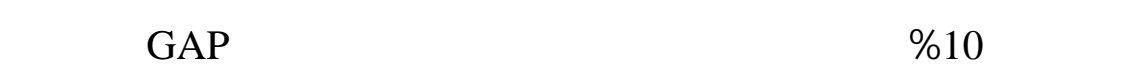

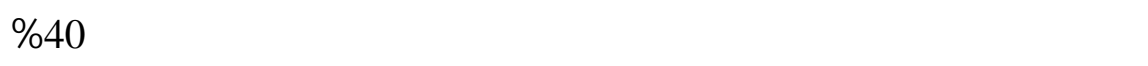

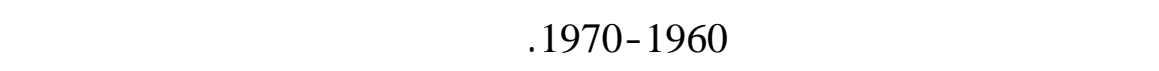

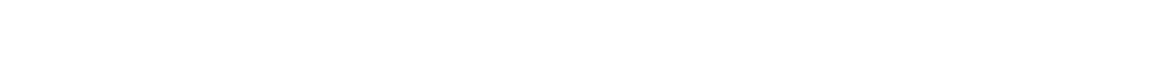

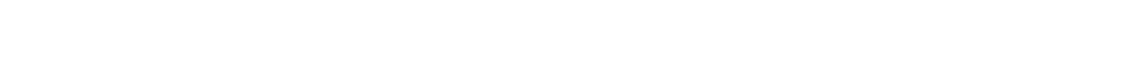

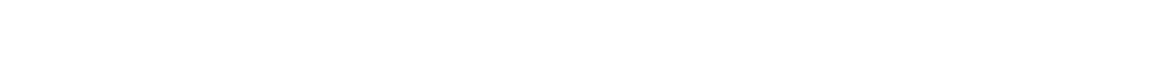
العراق بما يزيد علىستمائة ألف هكتار. (17)

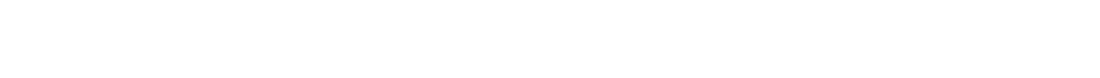

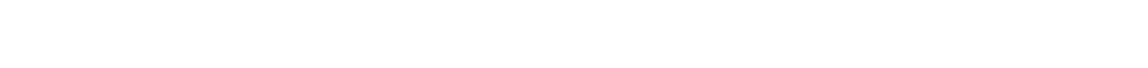

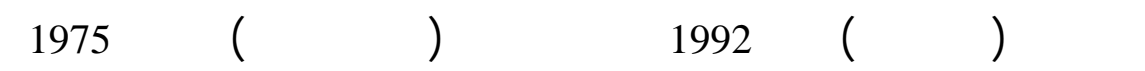

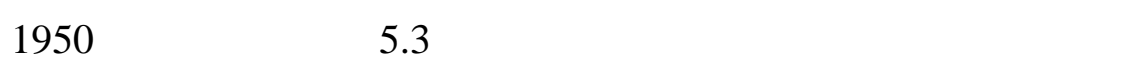

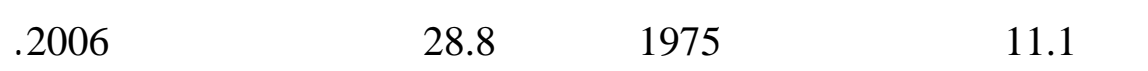

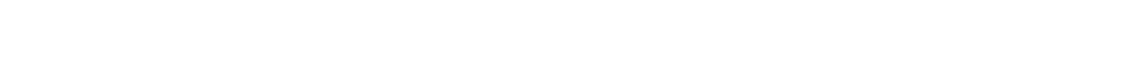
$\% 2$

إن الزياة السكانية الكبيرة التي حثت في العراق خلل العقود الخمسة

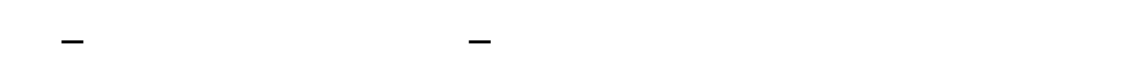

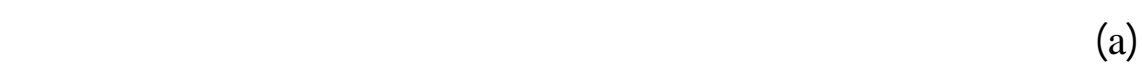

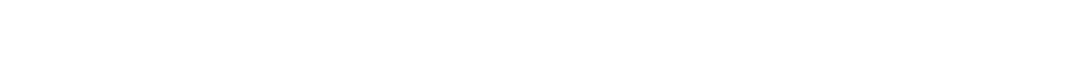


والاحتيلجلت المتزاية للتطاع الصناعي وتطاعلت الاقتصاد العراة مي الإنياح

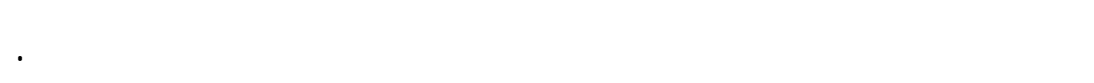

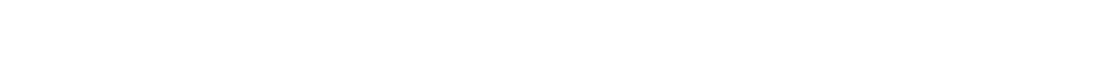

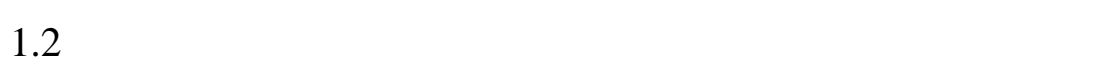

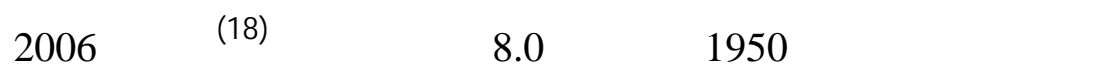

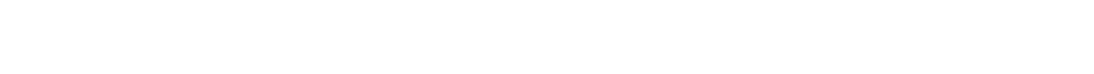

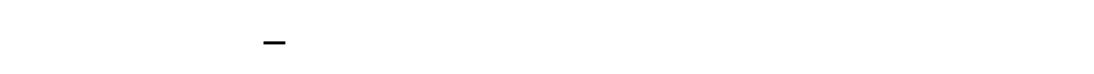
خاص. (19)

زياة متواصلة في الكمية المستخدة من الميله للس طحية والجوفي ة (b)

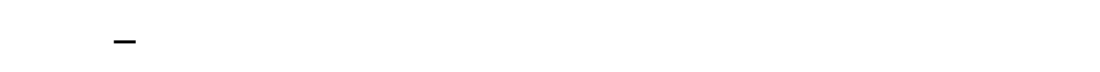

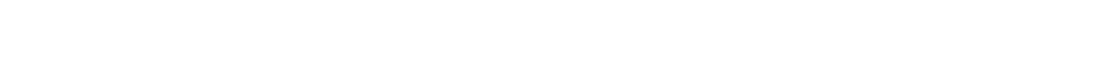

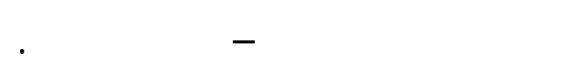

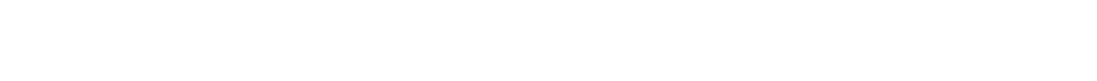

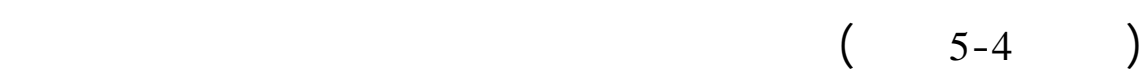

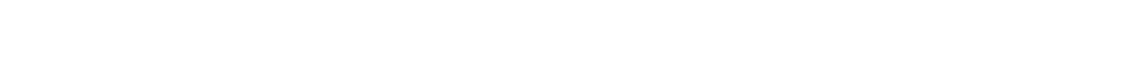

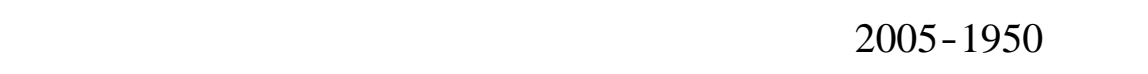
معل تدفقسنوي ثابت نسبياً لميل نجلة والفرات ذات المنايع التركية...

ثلنياً:عد أليسو، مشروع GAP وعملية إعلة إعمار الأهوارفي جنوب المرق:

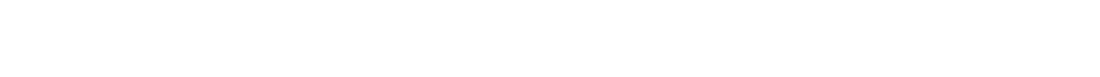

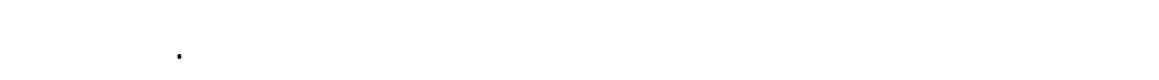

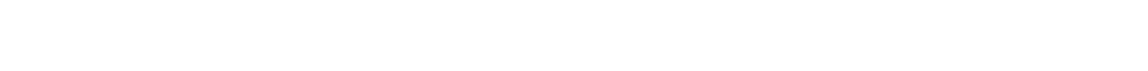

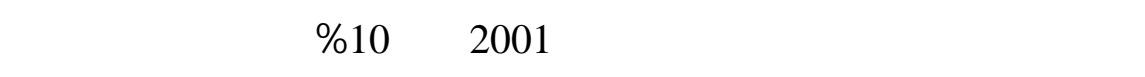


النصف الأول منسبعينات القرن الماضي (20)... كما يتضح ذل لك مـ ـن

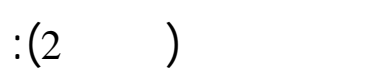

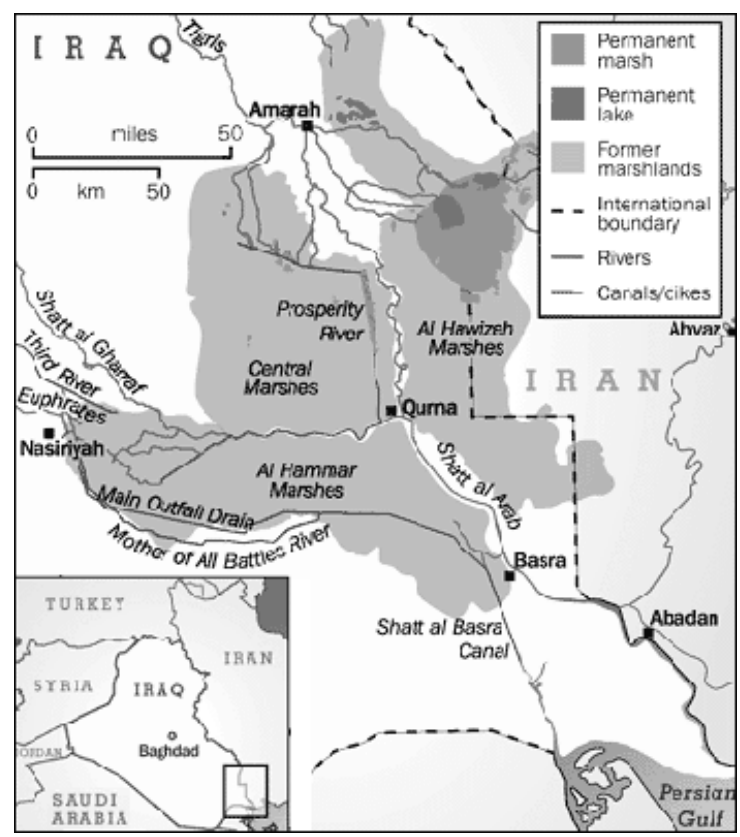

شكل (2): خاولة لأهوارجنوب الهرق كماكلت عليه في النصف الأل لمد بعينلت القرن المأضي وحجم الاختزل الني تعرضت له له عق علم المالم 2001.

في الشكل (أو بالأحرى الخارطة) أعلاه نجد أن المطقة المظللة باللون

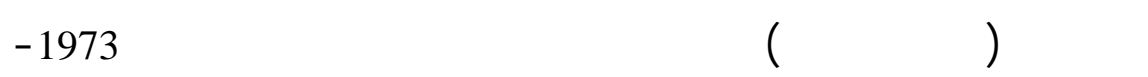

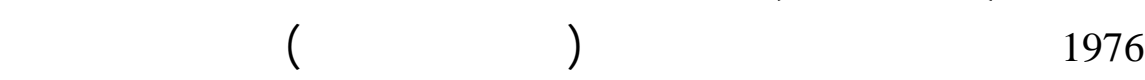

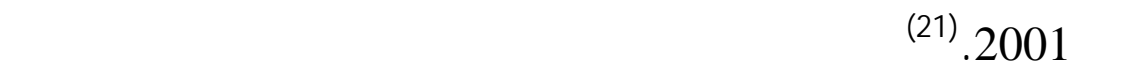

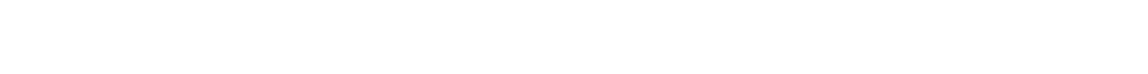

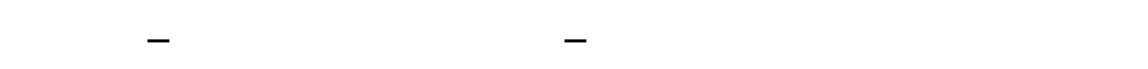




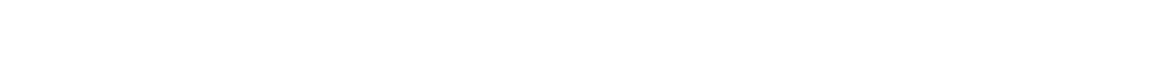

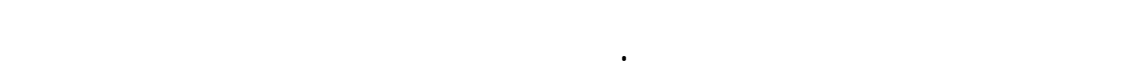

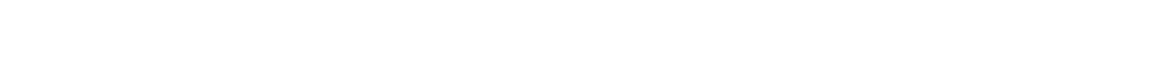

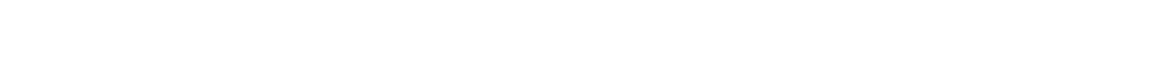

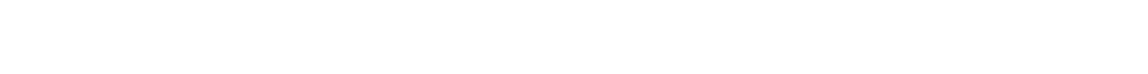

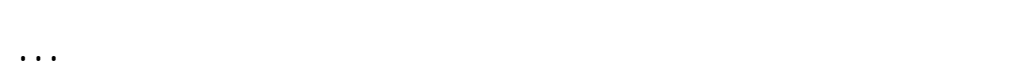

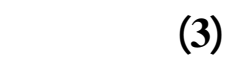

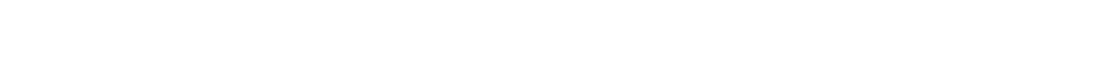

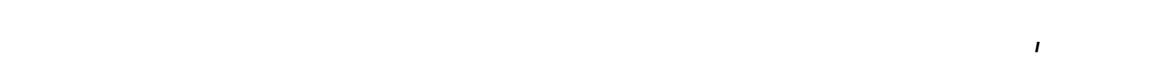

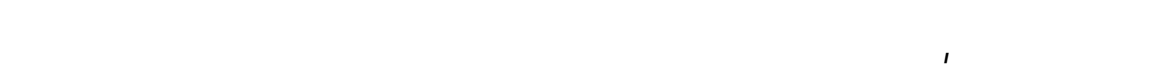

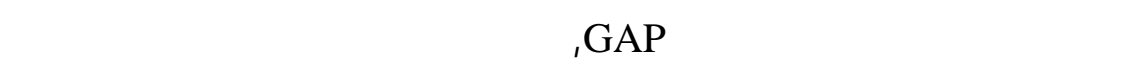

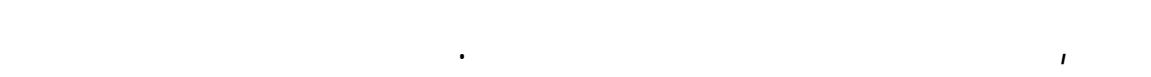

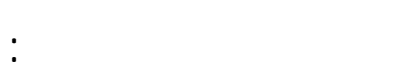

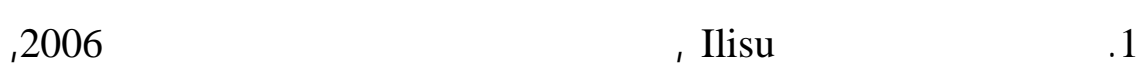

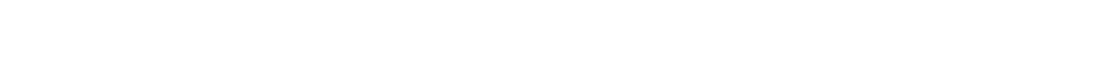

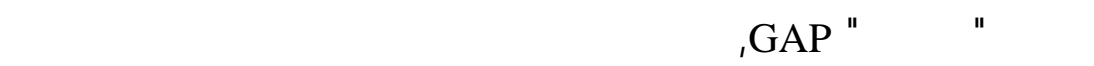

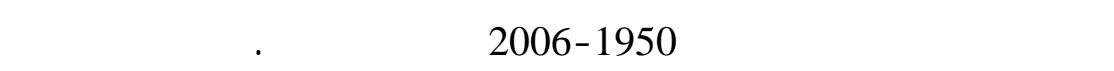

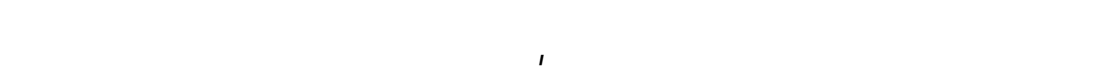

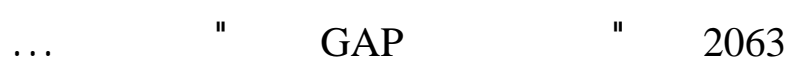

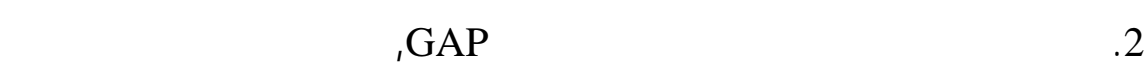

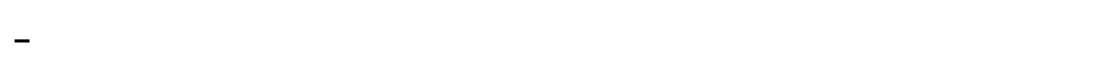

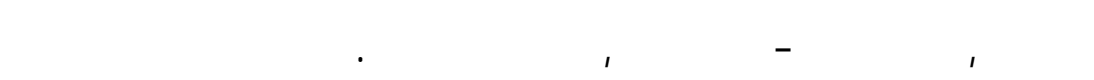


يختزل ذلك المعل إلى نحو 40\% مما كلن عليه خلل الفترة 1960 -

3. إن الزيادة للسكانية التيشهتها كل من تركيا والعراق خلل الفت ـرة

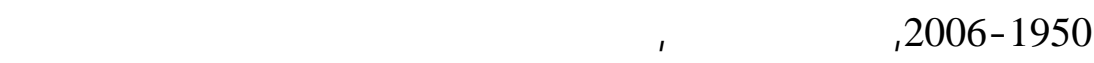

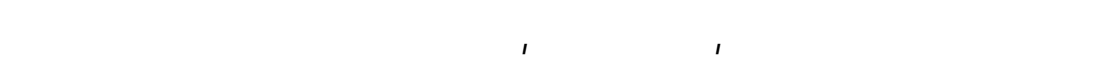

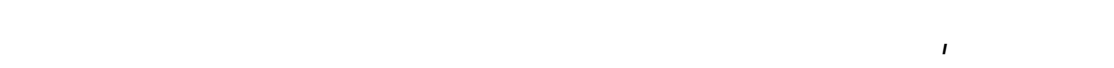

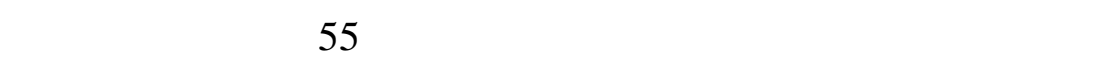

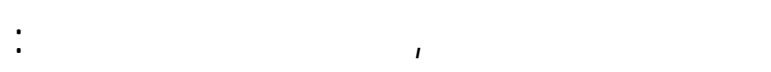

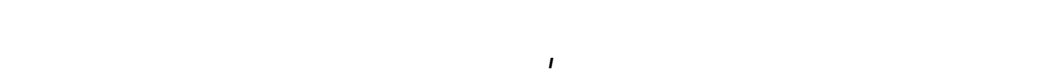

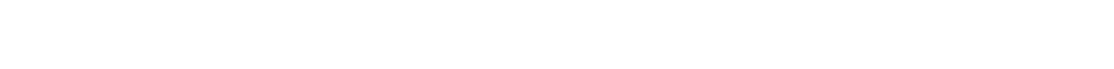

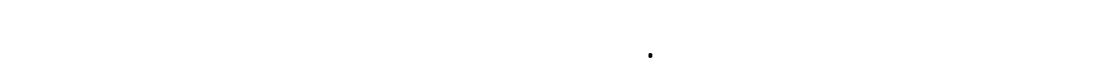

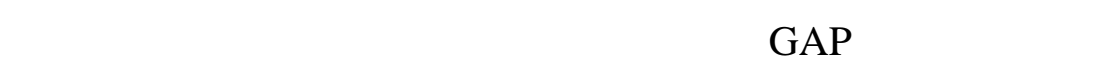

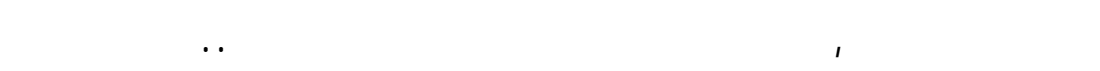

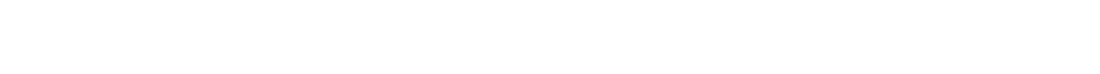

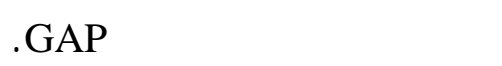

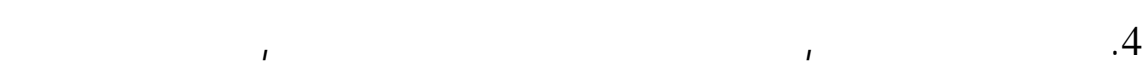

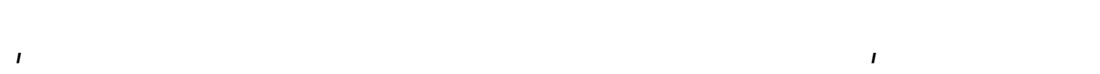

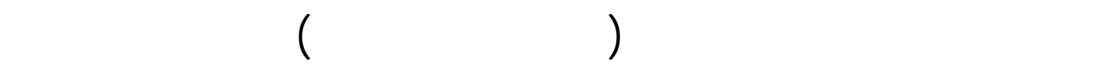

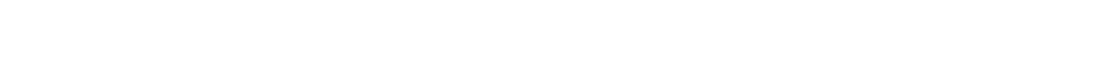

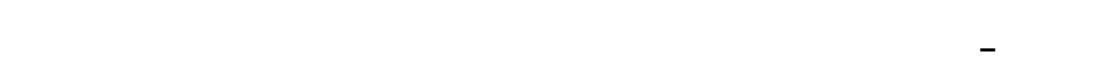

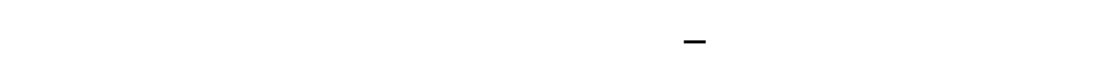

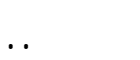
هذه هي أهم النتائج التي ققود إليها هذه الدرلسة الموجزة. 
(4) نالاث مقترحكت

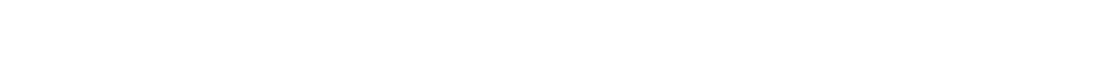
قلبل، نقود البلمث إلىطنالفح المقترحكت الثلاث التالية:

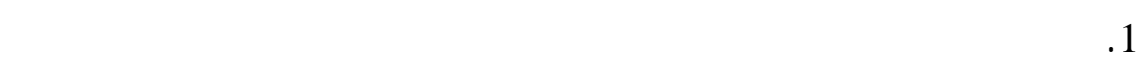

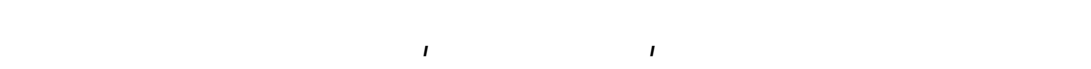

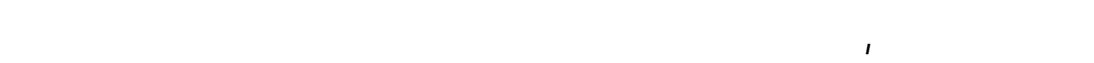

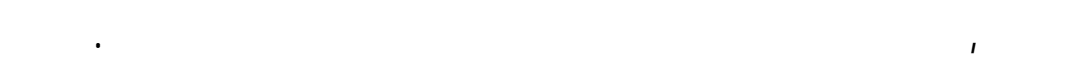

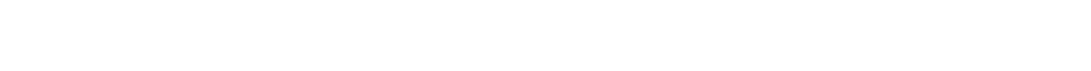

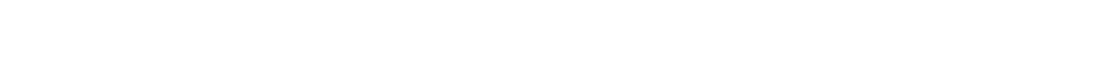

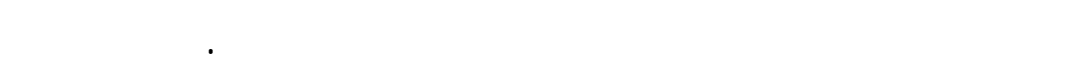

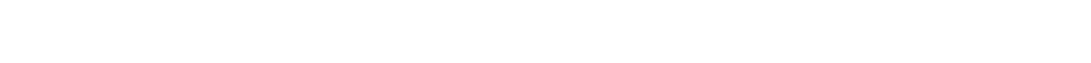

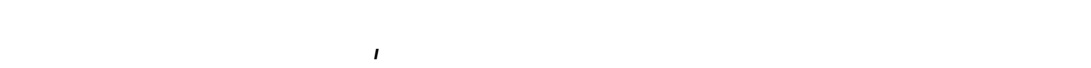

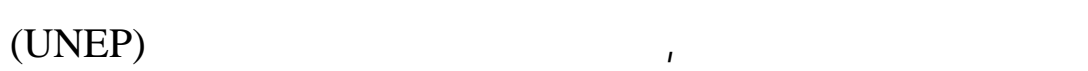

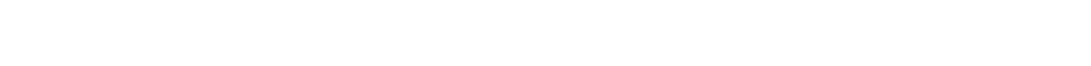

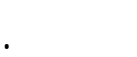

ولا يغيب عن البل إن عقد الفقية ثلاثيةشلملة خاص ـة باقتس لم

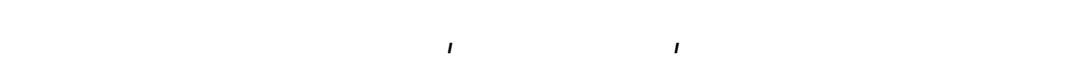

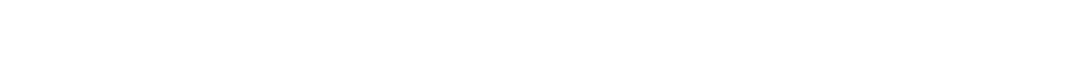

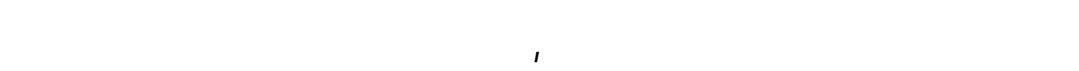
سدود مشروع GAP الخاصة بتوليد الطاقة الكهربائية.

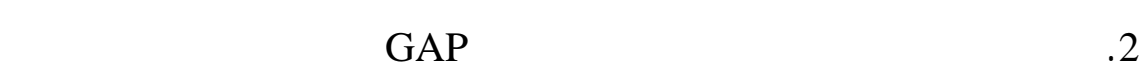

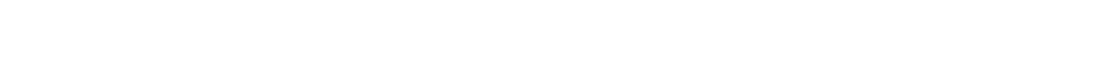

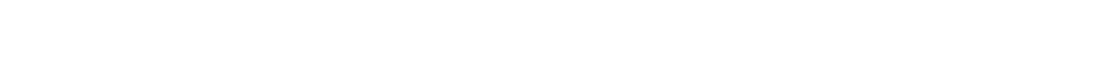

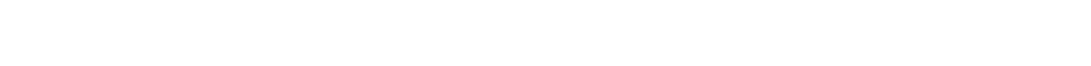


كقد مؤتمرسكالي إقليمي في أقرة أو سشق أو بغداد يتناول ما وراء

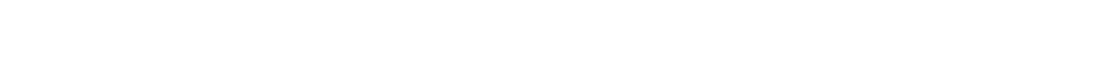

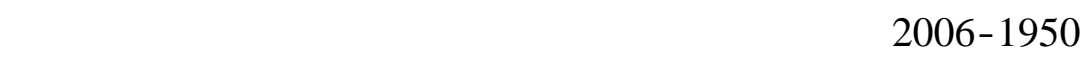

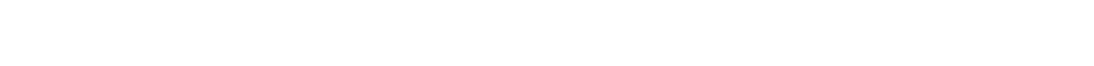

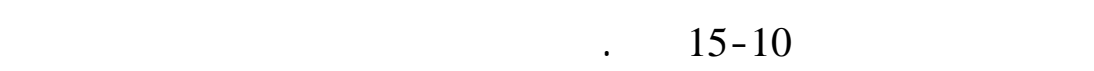

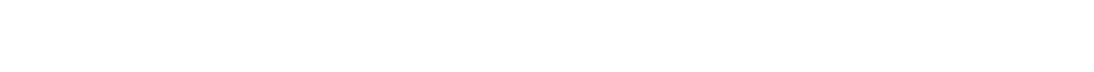
المسقبلية للجارتين تركيا وسوريا.

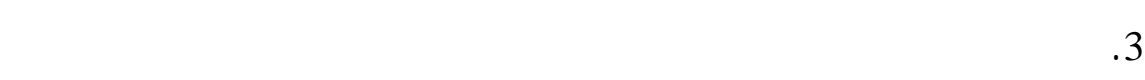

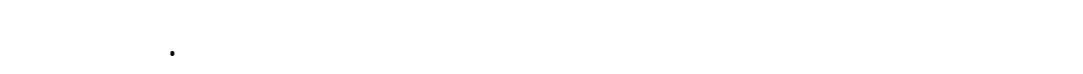

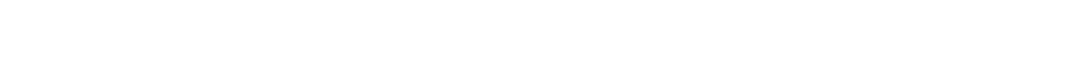

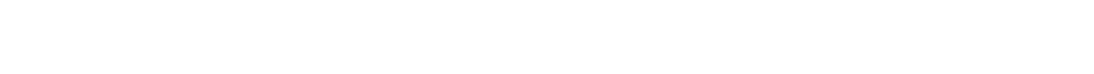

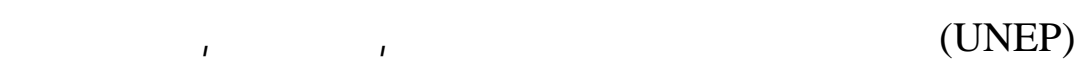

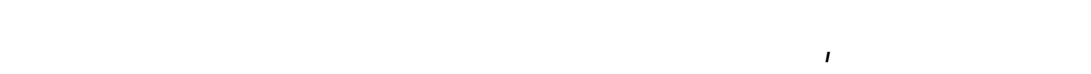
تركيا للمشاركة في هذا المؤتمر. هذا ما وددت تقديمه في هذه الدرلسة الموجزة، والـ ولي التوفيق. 


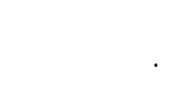

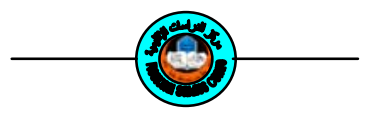

بعض الآثار المائية - الاقتصاية المحتملة

\title{
Some Possible Hydro-Economic Effects of Ilisu Dam Project Within the Overall Effects of Southeastern Anatolia Project (GAP)
}

\author{
Obey M. AL-Wattar* \\ Ecanamics Department, Faculty of Administration d Ecanamics, \\ Masul University, Iraq
}

\section{Aastract}

Economically, the Ilisu dam project, together with the other components of GAP, is a logical response to population growth which the Republic of Turkey witnessed over the period 1950-2006, and witnessing now (2008), as well as the developmental efforts undertaken by the Turkish government to enable the economy to absorb the growing labour force, and to reduce income and living inequality within the GAP region and between this region and the other regions of the Turkish economy. This necessitated, among other things, the expansion of agricultural productive capacity, thus actual agricultural production, not only to feed the rapidly increasing population as well as supplying the other sectors with agricultural inputs, but to avoid the possible worsening of the problem of priceinflation and current account deficit in Turkey. The growing population base, and the associated developmental efforts conducted by the Turkish government in the recent past, at present, and in the foreseeable future all are associated with a given average annual flow of the Euphrates-Tigris rivers (within Turkey) of no more than 55 billion cubic meter. Based on this fact, and other data, the author argues that - in the absence of a binding water sharing and water 
management agreement of the Euphrates-Tigris flow between Turkey and Iraq - if Turkey were to go ahead with the Ilisu dam, along with the other components of the GAP, the combined average annual flow of the Euphrates-Tigris rivers would be reduced, at the Iraqi borders, to some $40 \%$ of the $1960-1970$ average flow. The main conclusion of this study is, therefore, as follows: in the absence of the aforementioned agreement, the construction of Ilisu dam, along with the other components of GAP, may enable Turkey to achieve a sort of sustainable agricultural and economic development. However, that development will very likely be at the expense of agricultural development in Iraq... One of the victims of such "sustainable development", in Turkey, will almost certainly be the reconstruction project of the marshlands of Lower Mesopotamia.

Keywords: Population growth, Agricultural productive capacity, Irrigated land, Cereal output, Marshlands, Annual rate of flow, Ecosystem, Population conference, Binding water agreement. 


$$
\text { د. أبي الوتار }
$$

\section{الهولشن والمصادر}

(1) Postal, S. K. Last Oasis: Facing Water Scarcity, Worldwatch Environmental Alert Series (London: Norton \& Company, 1997), PP. 8083; Partow, H. "The Mesopotamian Marshlands: Demise of an Ecosystem", UNEP, Division of Early Warning and Assessment (Nairobi: 2001), PP. 7-8

(http://www.grid.unep.ch/activities/sustainable/tigris/marshlands/).

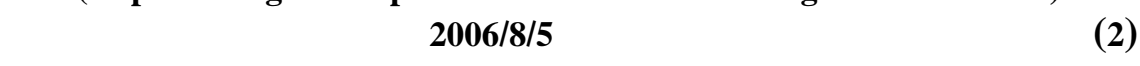

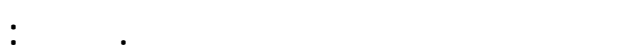

(File://E:ITURKSES Voice of Turks-Turkey begins Construction of Ilisu dam. htm).

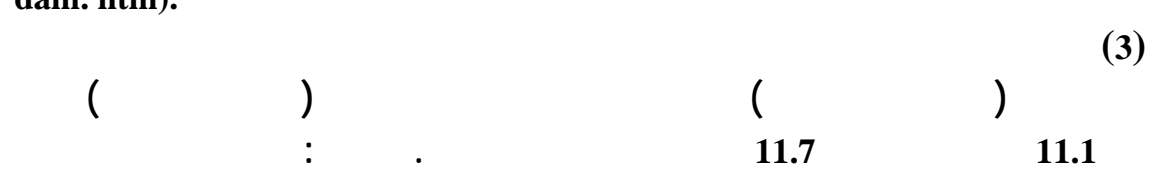

Partow, Ibid, PP. 45-46.

(4) Basshard, P. "Ilisu - a Test Case of International Policy Coherence", Bern Declaration, November 1998 (www.access.ch/evb/bd).

(5) Ohelsson, L. (ed.), Hydropoltitics: Conflicts Over Water As A Development Constraint (London: Zed Books, 1995), PP. 98-104; Postal, Ibid.; Richter, J. et al. (eds.), Strategies For Intersectoral Water Management in Devoloping Countries-Challenges For Agriculture, Proceedings of The International Workshop held from 6th to 10th May 1996 in Berlin, Germany (Berlin: German Foundation for International Development, 1997), PP. 178-181; See also: Wikipedia, Southeastern Anatolia Project (file://E: $\backslash$ Southeastern Anatolia Project- Wikipedia, the free encyclopedia.htm).

(6) Ibid.

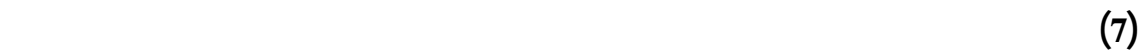

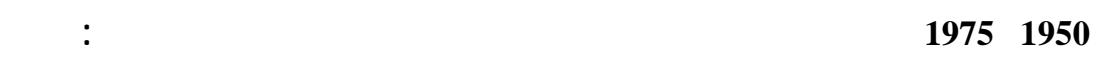

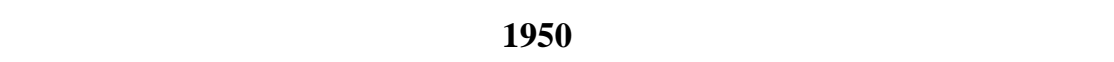

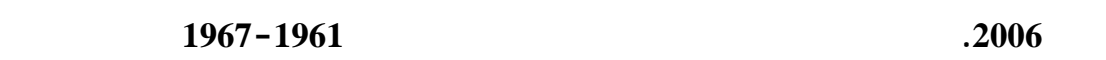

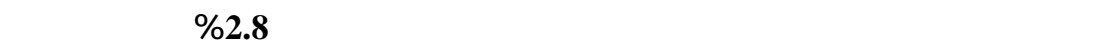

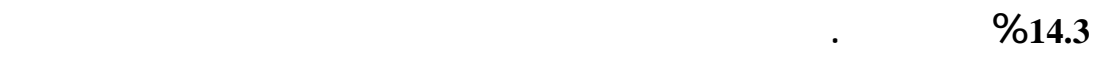

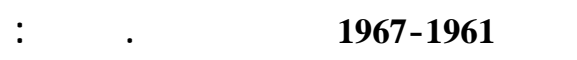


Todaro, M. Economic Development in the Third World, Fourth Edition, (Essex: Longman, 1989), P. 273.

\section{(8) أنمارعلسبل النل إله:}

Johnston, B. F. and Mellor, J. W. "The Role Of Agriculture In Economic Development", American Economic Review, Vol. LI, No. 4, Sept. 1961, PP. 571-581.

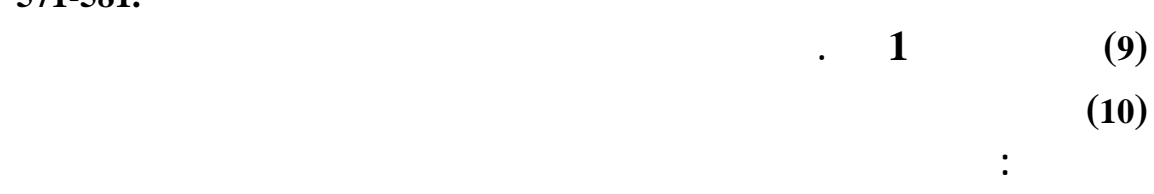

Koc, A. A. et al. "The Turkish Agricultural Policy Analysis Model", Technical Report 98-TR 42, November 1998m PP.4-5 (Center for Agricultural and Rural Development, Iowa State University, Ames, IA50011-1070); UNDP, Human Development Report 2007/2008, P.282.

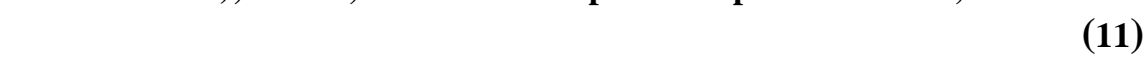

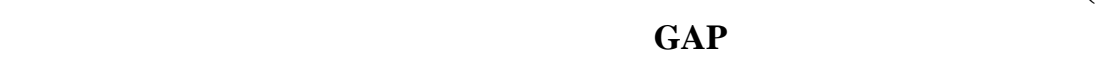

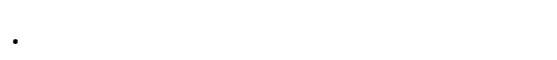
(12) بلانسة المرلفوبورا لدينا البيالت السكلية التلية:

\begin{tabular}{|c|c|c|c|c|c|c|}
\hline مهل انهو 2005 -2015 (\%) & 2006 & 2005 & 2000 & 1975 & 1950 & المولة \\
\hline 2.8 & 28.8 & 28.0 & 24.1 & 11.1 & 5.3 & لرف \\
\hline 2.2 & 19.3 & 18.9 & 16.2 & 7.5 & 3.5 & قرا \\
\hline
\end{tabular}

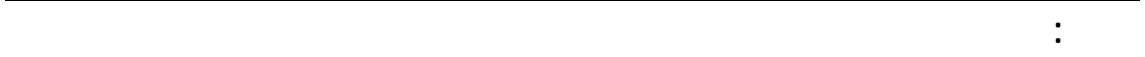

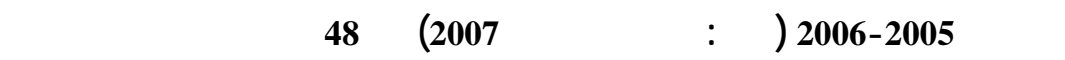

(13) Richter, et al., Ibid., PP. 117-118.

الص (1) (1)

(14) Ibid., P. 182.

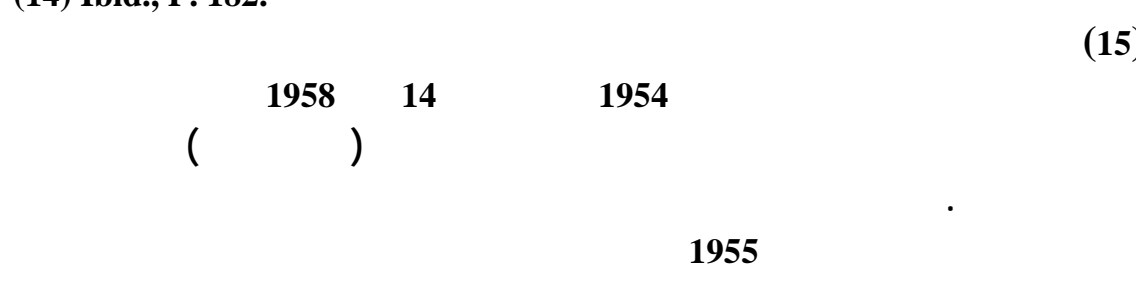




$$
\text { د. أبي الوتار }
$$

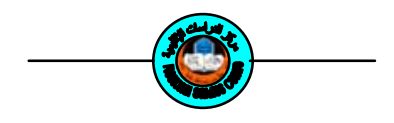
بعض الآثار المائية - الاقتصاية المحتملة

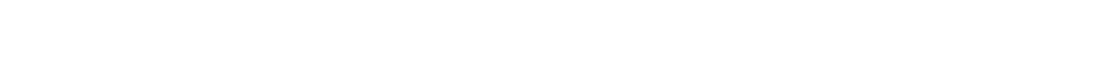

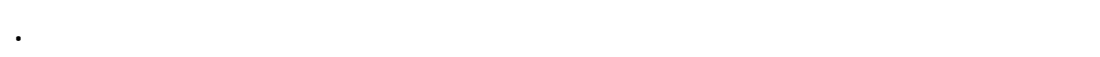

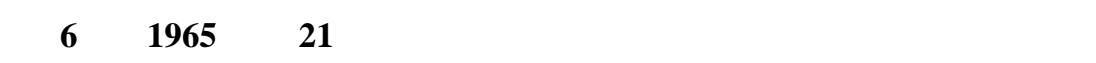

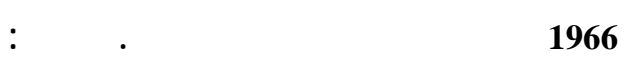

Gallman, W.J. Iraq Under General Nuri (Baltimore: Johns Hopkins Press, 1964), P. 29,36 (footnote); Penrose, E. and Penrose, E.F. Iraq: International Relations and National Development (London: Ernest Been, 1978), P. 334, 342-343.

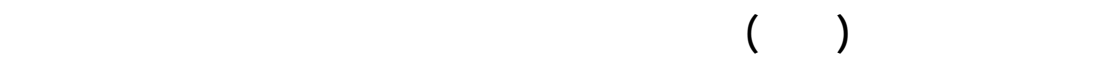

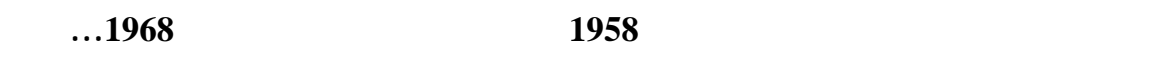

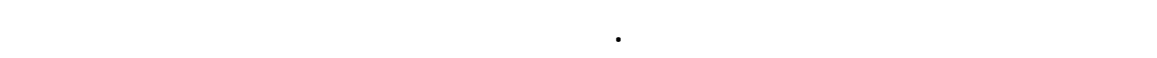

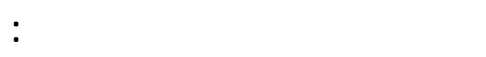

Penrose, Ibid., Chs. 12-15; Khadduri, M. Republican Iraq (London: Oxford University Press, 1969), Chs. 9-10.

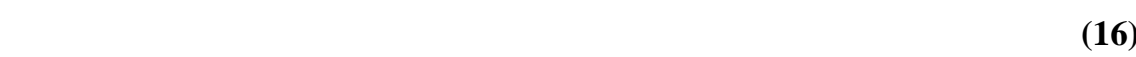

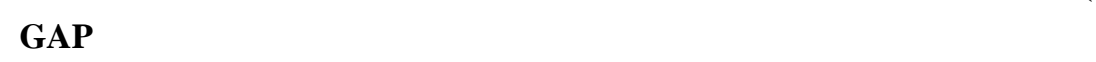

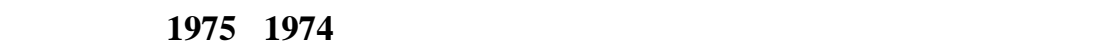

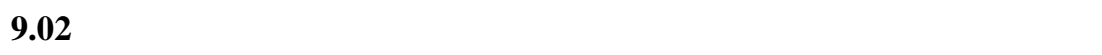

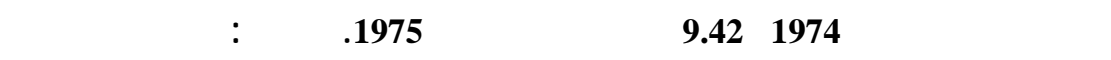

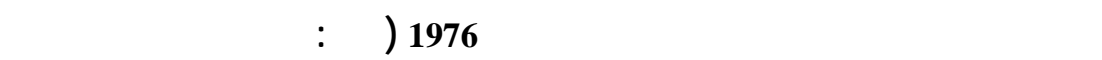

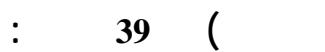

Ohelsson, Ibid., PP. 104-105.

(17) See: "Downstreem Impacts of Turkish Dam Construction on Syria and Iraq: Joint Report of Fact-Finding Mission to Syria and Iraq", Kurdish Human Rights Project, The Ilisu Dam Campaign, and The Corner House, United Kingdom, July 2002, PP. 19-20 (A common website is not available to the author).

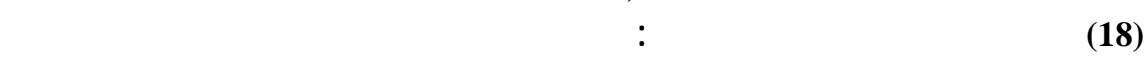

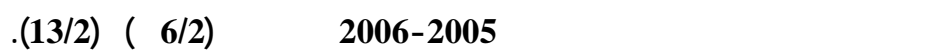

(19) Johnston and Mellor, Ibid.

(20) Parllow, Ibid., PP. 22-29.

(21) Ibid., PP. 30-31. 